\title{
Survey of international regional anesthesia fellowship directors
}

This article was published in the following Dove Press journal:

Local and Regional Anesthesia

28 June 2013

Number of times this article has been viewed

\section{Andrew K Lansdown ${ }^{1,2}$ \\ Paul G McHardy' \\ Sanjiv C Patel ${ }^{1,3}$ \\ Catherine $M \mathrm{Nix}^{\prime}$ \\ Colin JL McCartney'}

'Department of Anesthesia, Sunnybrook Health Sciences Centre, University of Toronto, Toronto, ON, Canada; ${ }^{2}$ University of Sydney, Sydney, NSW, Australia; ${ }^{3}$ University College Hospital, London, UK
Correspondence: Paul G McHardy Department of Anesthesia, Sunnybrook Health Sciences Centre, 2075 Bayview Avenue, Toronto, ON M4N 3M5, Canada

$\mathrm{Tel}+\mathrm{I} 4164804864$

Fax + I 4164806039

Email paul.mchardy@sunnybrook.ca
Background: The scope of regional anesthesia fellowship programs has not been analyzed but may provide insights that could improve fellowship training and standards.

Methods: Regional anesthesia fellowship directors across the world were asked to complete a comprehensive survey that detailed the range of educational and practical experience and attitudes as well as assessment procedures offered in their programs.

Results: The survey response rate was $66 \%$ (45/68). Overall, the range of activities and the time and resources committed to education during fellowships is encouraging. A wide range of nerve block experience is reported with most programs also offering acute pain management, research, and teaching opportunities. Only two-thirds of fellowships provide formal feedback. This feedback is typically a formative assessment.

Conclusion: This is the first survey of regional anesthesia fellowship directors, and it illustrates the international scope and continuing expansion of education and training in the field. The results should be of interest to program directors seeking to benchmark and improve their educational programs and to faculty involved in further curriculum development.

Keywords: anesthesia, regional, fellowship, education

\section{Background}

Interest in regional anesthesia (RA) has enjoyed resurgence in recent years, particularly with the introduction of the portable ultrasound machine. ${ }^{1,2}$ Quality education and training in RA techniques are essential to ensure safe and effective utilization of these techniques. Research has shown that traditional anesthesia residency programs rarely provide trainees with sufficient clinical experience and training to confidently utilize RA techniques when they begin independent consultant practice. ${ }^{3-5}$ This learning gap has driven demand for more advanced training. In response, the number of institutions offering fellowship positions in RA has grown, and these programs are available worldwide.

Guidelines for fellowship training in RA were first published by the American Society of RA (ASRA) in $2005 .{ }^{6}$ The purpose of this effort was to recommend an organizational and educational framework to promote modern and comprehensive fellowship training in RA and pain medicine. The guidelines recommend a number of scholarly and practice-based learning activities, which may be incorporated into a fellowship program. Since there is no requirement to follow these when developing an RA fellowship, ${ }^{7}$ the clinical and theoretical instruction and range of experience offered across programs may vary widely. 
The purpose of this study is to survey RA fellowship directors around the world. The primary aim is to establish the range, consistency, and quality of education programs and experience available in these programs. The secondary aims are to illuminate the major barriers to establishing formalized teaching programs and to gauge expert opinion on the most important educational objectives and resources for RA fellows. We postulate that there is a highly variable approach to RA education and experience across fellowship programs, which may affect the quality of the fellowship experience. This data will be of interest worldwide to fellowship directors seeking to benchmark and improve their educational programs and to faculty involved in further curriculum development. The results will also be of interest to potential fellows who need a standard when choosing programs.

\section{Methods}

Ethics approval to undertake a survey of worldwide RA fellowship directors was obtained from the Sunnybrook Health Sciences Center research ethics board. Directors of all RA fellowship programs known to the authors from around the world were asked to complete the survey. Potential participants were identified from the ASRA database for RA fellowships, comprehensive Google searches for international RA fellowship positions (keywords: "regional anesthesia" and "fellowship"), and word-of-mouth referral, starting from those known to the authors. Eligible respondents were required to have a RA fellowship program in place at the time of completion of the survey. Participants were aware that the information they provided would be held individually confidential but that the pooled information would be analyzed and undergo publication.

Fellowship directors were contacted by email and asked to complete an Internet-based survey. ${ }^{8}$ Initial emailing was conducted in November 2011. The survey was open for 60 days, and nonresponders received a first reminder email after 15 days and a final reminder after 40 days.

The survey was organized into six major sections: (1) demographic information (country, fellowship positions per year, years of fellowship, experience of faculty); (2) educational experience (time allocated, range of didactic and practical education activities, availability of educational resources, involvement of nonanesthesia personnel in education); (3) attitudes toward education (importance, optimum time to be allocated, rating the usefulness of various educational activities); (4) extent of experience in peripheral blockade (range and quantity, level of supervision); (5) extent of nontechnical experience (research, teaching, acute pain service, pediatric and obstetric experience); and (6) fellow assessment (whether a formal assessment process exists and how often, what methods are utilized, and what is the best means for assessment).

Data from the survey were collected into a database (Microsoft Excel 2011; Microsoft Corporation, Redmond, WA, USA) for analysis. The data was summarized by proportions and percentages or median and interquartile range (IQR). Data are rounded to the nearest whole.

\section{Results}

Sixty-eight international RA fellowship directors were contacted (USA, 39; Canada, 11; UK/Ireland, 6; Europe, 2, Australia/New Zealand, 10). A total of 45 responses were returned, for an overall response rate of $66 \%$. Three respondents did not have a RA fellowship program and were therefore excluded resulting in a report based on 42 international RA fellowship directors. Not all respondents answered every question. For questions where there were less than 42 responses, proportions, and calculation of percentages were based on the number of answers to each question.

\section{Respondent characteristics}

The distribution and characteristics of respondents are shown in Table 1. No responses were obtained from continental Europe; otherwise, respondents represent a good spread of international RA fellowship programs, albeit with the greatest proportion from North America. Over $80 \%$ of programs offer only one to two positions per year. Although $50 \%$ of programs have been established for 5 or more years, there are still a number of newer programs appearing. Almost $90 \%$ of programs had at least one staff anesthesiologist who had completed formal RA fellowship training. The RA workload varied widely across the surveyed institutions, ranging from 200 to 25,000 RA procedures performed per year, with a median of approximately 4000 (IQR 2655-5344).

\section{Education}

On a five-point Likert scale, rating the overall importance of a formal education program during RA fellowship training, 14/41 (34\%) rated it as "extremely important," 10/41 (24\%) "very important," 13/41 (32\%) "moderately important," 4/41 (10\%) "slightly important," and 0/41 "not at all important." Only two programs (5\%) did not allocate 
Table I Respondent characteristics

\begin{tabular}{lll}
\hline & $\mathbf{n}$ & $\%$ \\
\hline Country & & \\
USA & $26 / 42$ & $62 \%$ \\
Canada & $7 / 42$ & $17 \%$ \\
UK/Ireland & $4 / 42$ & $10 \%$ \\
Europe & $0 / 42$ & $0 \%$ \\
Australia & $5 / 2$ & $12 \%$ \\
Number of fellowships positions per year & \\
I & $19 / 42$ & $45 \%$ \\
2 & $15 / 42$ & $36 \%$ \\
3 & $5 / 42$ & $12 \%$ \\
4 & $2 / 42$ & $5 \%$ \\
5 & $0 / 42$ & $0 \%$ \\
$>5$ & $1 / 42$ & $2 \%$ \\
Years of fellowship program & & \\
$<1$ & $1 / 42$ & $2 \%$ \\
I & $4 / 42$ & $10 \%$ \\
2 & $9 / 42$ & $21 \%$ \\
3 & $1 / 42$ & $2 \%$ \\
4 & $3 / 42$ & $7 \%$ \\
$5-10$ & $13 / 42$ & $31 \%$ \\
$>10$ & $8 / 42$ & $19 \%$ \\
Staff with RA fellowship training & & $12 \%$ \\
0 & $5 / 42$ & $12 \%$ \\
I & $5 / 42$ & $24 \%$ \\
2 & $11 / 42$ & $10 \%$ \\
3 & $4 / 42$ & \\
4 & $5 / 42$ & \\
$5-10$ & $10 / 42$ & \\
$>10$ & $2 / 42$ & \\
\hline
\end{tabular}

Abbreviations: $n$, number; $R A$, regional anesthesia.

any time for educational activities (not including research). While 13 programs $(31 \%)$ provided 8 or more hours of education per week, the median time allocated was 5 hours per week (IQR 2-8 hours). When asked, "How many hours per week should be scheduled for RA education sessions?" only $1 / 41$ respondents $(2 \%)$ selected "none," with a median of 4 hours (IQR 1-7 hours). A wide range of educational activities, resources, and personnel are utilized across the surveyed fellowship programs (see Table 2). The most common didactic activity was journal club and evidence-based medicine review in $34(81 \%)$ programs, while live model sonography was the most common practical education activity, utilized in 35 (83\%) programs. Twenty-six (62\%) utilized nonanesthesia staff in the delivery of their educational program, with pain specialists most commonly involved. The pooled average rating of importance for each educational activity is presented in Figure 1. Live model sonography workshops were rated as the most important overall teaching method for RA fellowships.
Table 2 Educational activities, resources, and personnel

\begin{tabular}{|c|c|c|}
\hline & $\mathbf{n}$ & $\%$ \\
\hline \multicolumn{3}{|l|}{ Didactic educational activity } \\
\hline Lecture series & $27 / 42$ & $64 \%$ \\
\hline Journal club and EBM review & $34 / 42$ & $81 \%$ \\
\hline Case presentations & $24 / 42$ & $57 \%$ \\
\hline Morbidity and mortality meetings & $28 / 42$ & $67 \%$ \\
\hline Online modules & $9 / 42$ & $21 \%$ \\
\hline \multicolumn{3}{|l|}{ Practical education activities } \\
\hline Cadaver dissection & $22 / 42$ & $52 \%$ \\
\hline Cadaver sonography & $14 / 42$ & $33 \%$ \\
\hline Live model sonography & $35 / 42$ & $83 \%$ \\
\hline Phantom training & $29 / 42$ & $69 \%$ \\
\hline Block videography and appraisal & I I/42 & $26 \%$ \\
\hline \multicolumn{3}{|l|}{ Educational resources } \\
\hline Ultrasound phantom models - 3D & $33 / 42$ & $79 \%$ \\
\hline Anatomy training software & $9 / 42$ & $21 \%$ \\
\hline Textbook and journal library & $42 / 42$ & $100 \%$ \\
\hline Educational website (eg, nysora.com) & $34 / 42$ & $81 \%$ \\
\hline \multicolumn{3}{|l|}{ Nonanesthesia staff involved in education } \\
\hline Pain specialists & $19 / 42$ & $45 \%$ \\
\hline Nurse specialists & $11 / 42$ & $26 \%$ \\
\hline Anatomists & $7 / 42$ & $17 \%$ \\
\hline Surgeons & $6 / 42$ & $14 \%$ \\
\hline Radiologists/sonographers & $1 / 42$ & $2 \%$ \\
\hline None & $16 / 42$ & $38 \%$ \\
\hline
\end{tabular}

The number of blocks (excluding neuraxial) performed or supervised by fellows varied widely. Although most participated in more than 15 blocks per week, a number of programs offered less experience (see Table 3 ). Of the blocks performed by fellows, the majority were supervised by staff anesthesiologists. In 29/41 (71\%) of programs, fellows kept a compulsory logbook of block experience. The extent of fellow block experience is presented in Figure 2. Of the techniques surveyed, the femoral nerve block is the most commonly performed lower limb block, and the interscalene block is the most commonly performed upper limb block. Most fellowship programs offered RA experience outside orthopedic surgery, with vascular, thoracic, and pediatric experience being the most common (see Table 3). Almost all fellows participated in acute pain service rounds, resident RA teaching, and research activities during their program. When offered, the time allocated for research activities was 0.5 day per week in 11/34 (32\%), 1 day in 19/34 (56\%), 2 days in $3 / 34(9 \%)$, and more than 2 days per week in 1/34 (3\%).

\section{Evaluation}

Most programs had processes for formal evaluation of their fellows (see Table 4). Feedback was usually provided every quarter. Of the various assessment methods surveyed, 


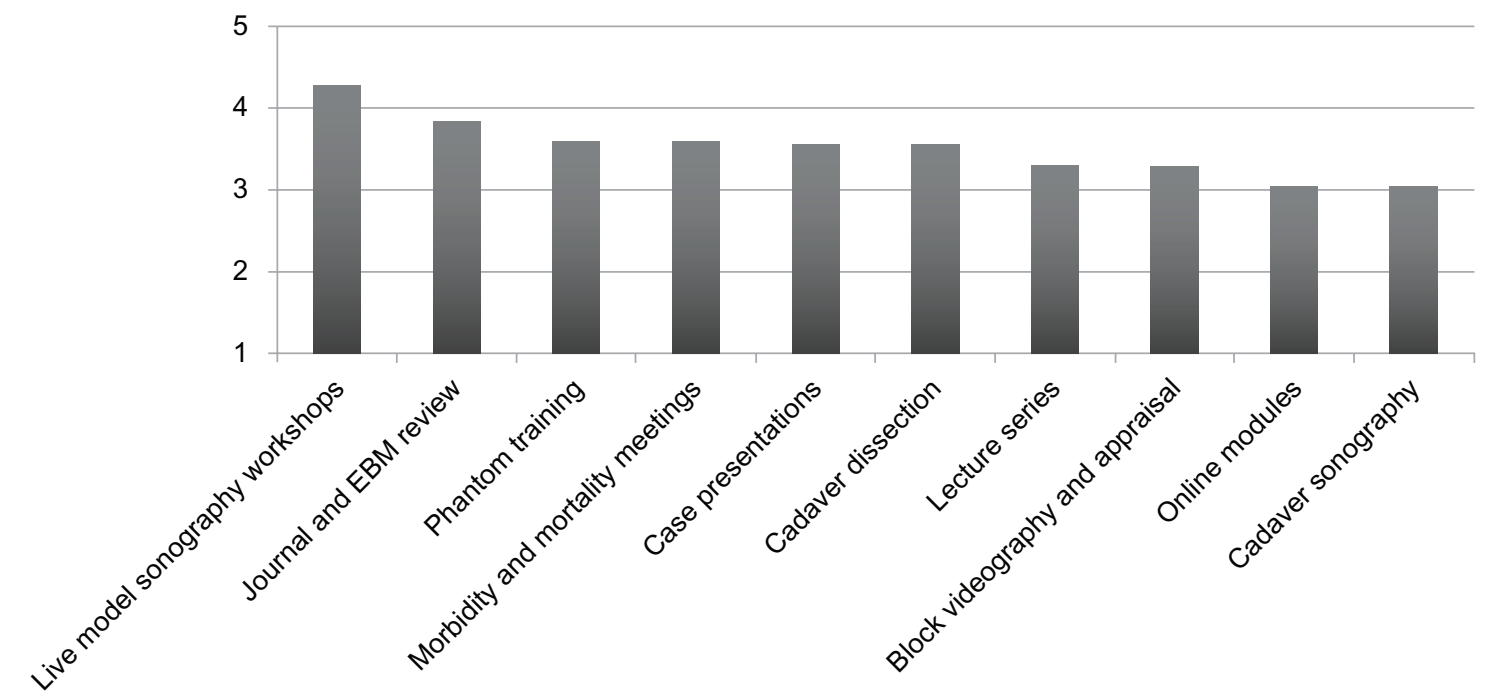

Figure I Education activity versus mean rating of importance.

Note: Scores: I, not important; 2, slightly important; 3, moderately important; 4, very important; 5 , extremely important. Abbreviation: EBM, evidence-based medicine.

evaluation by supervising staff anesthesiologists and logbook review were the most commonly used methods in 28/28 $(100 \%)$ and 22/28 (79\%) programs, respectively (see Table 4). Other assessment methods listed by respondents included resident evaluation of fellow teaching and European Society of RA diploma. When asked, "Should there be a standard

Table 3 Clinical and nonclinical experience

\begin{tabular}{lll}
\hline & $\mathbf{n}$ & $\%$ \\
\hline Blocks (excluding neuraxial) per week? & $2 / 4 \mid$ & \\
I-5 & $4 / 4 \mid$ & $5 \%$ \\
$6-10$ & $7 / 4 \mid$ & $10 \%$ \\
$\mid I-15$ & $|0 / 4|$ & $17 \%$ \\
I6-20 & $|8 / 4|$ & $24 \%$ \\
$>20$ & $0 / 4 \mid$ & $44 \%$ \\
Percentage of blocks supervised by staff anesthesiologists? & \\
$0 \%$ & $1 / 4 \mid$ & $0 \%$ \\
$<25 \%$ & $7 / 4 \mid$ & $2 \%$ \\
$26 \%-50 \%$ & $5 / 4 \mid$ & $17 \%$ \\
$51 \%-75 \%$ & $8 / 4 \mid$ & $12 \%$ \\
$76 \%-100 \%$ & $20 / 4 \mid$ & $20 \%$ \\
I00\% & & $49 \%$ \\
Nonorthopedic RA experience & $21 / 4 \mid$ & \\
Pediatric & $29 / 4 \mid$ & $51 \%$ \\
Vascular & $22 / 4 \mid$ & $71 \%$ \\
Thoracic & $|6 / 4|$ & $54 \%$ \\
Obstetric & $|I / 4|$ & $39 \%$ \\
Interventional chronic pain & $37 / 4 \mid$ & $27 \%$ \\
Acute pain service & $|2 / 4|$ & $90 \%$ \\
Other & & $29 \%$ \\
Nonclinical experience & $39 / 4 \mid$ & $95 \%$ \\
Resident RA teaching & $34 / 4 \mid$ & $83 \%$ \\
Research & & \\
\hline Ab & &
\end{tabular}

Abbreviations: $n$, number; $R A$, regional anesthesia. process for the formal evaluation of RA fellow knowledge and clinical competency?" the majority (32/41) of fellowship directors answered yes. Respondents were asked to rank the usefulness of six methods for fellow assessment. The majority of the respondents to this question (87\%) gave "evaluation by supervising staff anesthesiologist," the highest average rating.

\section{Discussion}

RA fellowships are found across the world, though some fellowships were not identified in this survey. North America accounts for the majority of positions, which suggests that the ASRA plays a central role in providing direction and guidance in RA fellowships locally and internationally. While many regional fellowship programs are now well established, there is still a large number that have emerged over recent years as demand for advanced training in the field continues to grow.

Overall, the range of activities and the time and resources committed to education during RA fellowships is encouraging. Most programs provide a combination of didactic and practical education, with didactic activities being more common. This is not surprising since these sessions, which include lecture series, journal review, or case discussions are inexpensive and are generally easy to schedule. Although didactic teaching has been the tradition in medical education, there is a shift towards greater emphasis on practical education, particularly in the technical disciplines. ${ }^{9}$ Proficiency in RA necessitates acquisition of technical skills in addition to the theoretical knowledge, and 


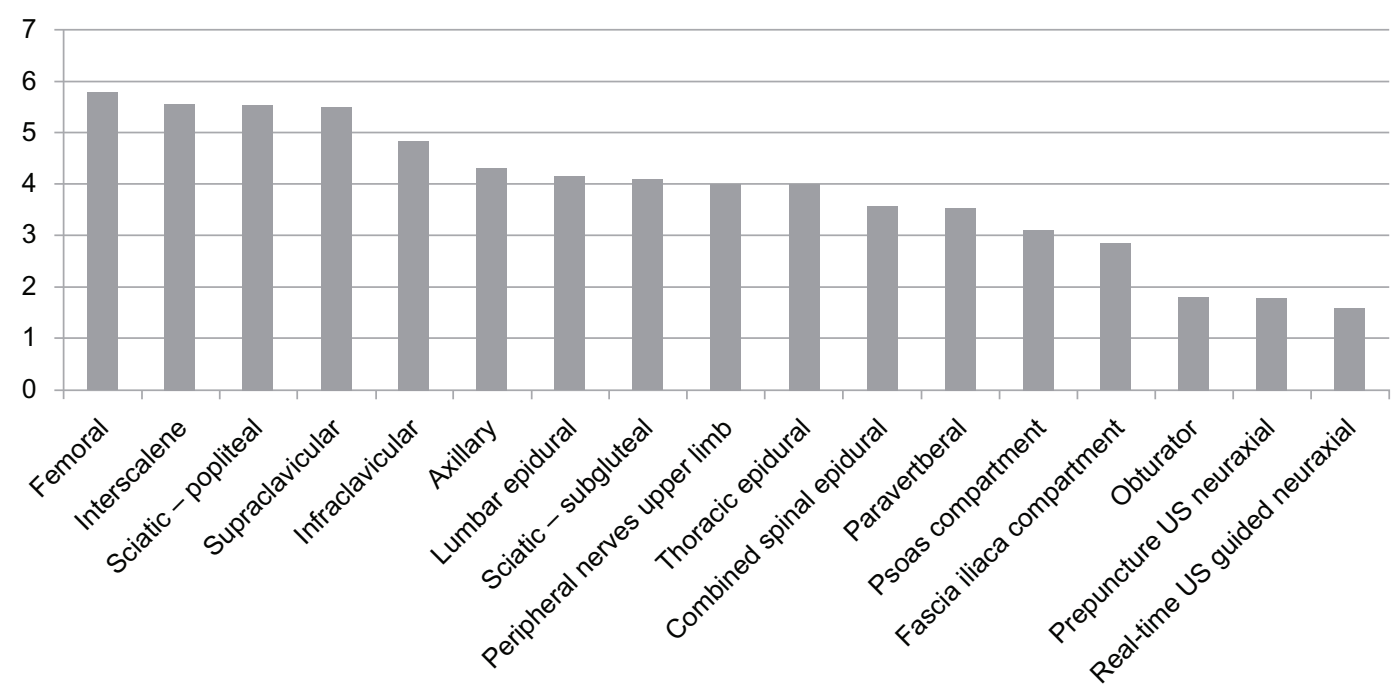

Figure 2 Nerve blocks versus mean experience offered during fellowship. The y-axis represents the respondent's claimed frequency of practice for each particular block at their institution with a score of I being never performed and a score of 7 being commonly performed.

Abbreviation: US, ultrasound.

as yet there is no consensus on the best way to acquire this technical competence. ${ }^{10,11}$

Live model sonography is a popular educational activity among fellowship programs. This too is unsurprising as it is inexpensive and easy to organize, and participants can quickly learn sonographic anatomy, which is fundamental to the practice of ultrasound-guided RA. One limitation is that it does not allow for training in real-time, probe-needle alignment. Cadaveric specimens, appropriately prepared, can be used as a realistic model for ultrasound-guided RA. ${ }^{12}$ Without time constraints or patient discomfort, confidence and skill in tracking the needle to the target can be achieved

Table 4 Fellow assessment

\begin{tabular}{|c|c|c|}
\hline & $\mathbf{n}$ & $\%$ \\
\hline \multicolumn{3}{|l|}{ Do you provide formal feedback? } \\
\hline No & $|3 / 4|$ & $32 \%$ \\
\hline Yes (see additional questions below) & $28 / 41$ & $68 \%$ \\
\hline \multicolumn{3}{|l|}{ How often is formal feedback provided? } \\
\hline 3 monthly & $20 / 28$ & $71 \%$ \\
\hline 6 monthly & $6 / 28$ & $21 \%$ \\
\hline 12 monthly & $2 / 28$ & $8 \%$ \\
\hline \multicolumn{3}{|l|}{ Which assessment methods are used? } \\
\hline Evaluation by staff anesthesiologists & $28 / 28$ & $100 \%$ \\
\hline Evaluation by nursing and allied health staff & $6 / 28$ & $21 \%$ \\
\hline Theory examination/assessment & $9 / 28$ & $32 \%$ \\
\hline Practical examination/assessment & $4 / 28$ & $14 \%$ \\
\hline Logbook review & $22 / 28$ & $76 \%$ \\
\hline Online module completion & $22 / 28$ & $79 \%$ \\
\hline Other & $3 / 28$ & $11 \%$ \\
\hline \multicolumn{3}{|l|}{ Should there be a standard assessment? } \\
\hline Yes & $32 / 41$ & $78 \%$ \\
\hline No & $9 / 41$ & $22 \%$ \\
\hline
\end{tabular}

Abbreviation: $\mathrm{n}$, number. in a stress free environment. It is especially useful for the rehearsal of more technically difficult blocks or those that are infrequently encountered. Cadaver sessions are popular with trainees and are a proven educational tool in the anesthetic literature. ${ }^{2,13}$ Cadaveric sonography is offered in a number of fellowship programs, but it may in some cases prove to be exceptionally difficult to achieve due to cost and inaccessibility. Pooling resources and participants between collaborating institutions may make this a feasible activity for more fellowship programs. On the other hand, advancement in RA simulation technology may fill this learning gap and prove to be more cost effective and easier to administer in the longer term. ${ }^{14}$

RA fellowships offer a wide range of block experience. In general, there is well-balanced exposure to lower and upper limb techniques. Ultrasound-assisted neuraxial blocks are among the most infrequently performed techniques amongst fellows. There is no consensus on the optimum number of blocks required to achieve competency in RA procedures, yet all programs exceed the minimum standard expected for a typical anesthesia residency program. ${ }^{8}$ Large variations do exist, with some programs reporting fewer than five blocks per fellow per week. Although we continue to use block numbers performed as a serious measure of competence, as Joseph Neal pointed out in his 2011 Carl Koller address, there are many other important aspects to consider in RA training. ${ }^{15}$ These features are not easy to measure in a survey. Compared to previous surveys, ${ }^{16}$ it is encouraging to see improved opportunities for fellow colleagues to acquire experience outside orthopedic RA, with pediatric, thoracic, 
and obstetric RA commonly seen. Almost all fellows are involved in acute pain service rounds, teaching, and research.

One surprising finding was the high level of direct supervision of fellows during block performance. As a technical discipline, RA requires the acquisition of procedural skills that can only be learned through practice and repetition. How much of this practice should be supervised directly, and how much should be carried out independently are important questions. While close supervision may offer opportunities for bedside teaching and possibly improved block success and safety, it can limit independence and negatively impact confidence and proficiency when fellows transition to autonomous practice. ${ }^{17,18}$ In a series of studies examining motor learning, individuals who were given feedback after every trial of performing simple tasks learned faster than individuals who were given summary feedback after a series of trials. ${ }^{19-21}$ Once the feedback was discontinued, however, the individuals who had only received feedback after a group of trials maintained their performance at a much higher level, suggesting that heavily supervised motor learning can limit skill retention and proficiency in the longer term.

Overall two-thirds of programs formally assessed their RA fellows, despite the recommendations of guidelines such as those of the ASRA curriculum. Where fellow assessment was undertaken, the processes seem to be more formative in nature, with staff evaluation universally employed. Nevertheless, at least three-quarters of programs include a practical examination or assessment and 14\% hold a theory examination or assessment as part of their evaluation. Logbook review was also commonly utilized although no universal benchmark for adequate scope of experience exists.

The ideal means for fellow assessment is unclear. ${ }^{22}$ The benefit of formative assessments that primarily focus on subjective feedback of performance is that they promote reflection and typically encourage further learning. The drawback is that the assessments can suffer from bias, produce a wider range of qualitative results based on individual experiences - not necessarily related to the curriculum and are more difficult to process into a cohesive evaluation. Summative assessments are useful because they can act as an incentive for learning a specified curriculum and can effectively shape a standardization process. ${ }^{23}$ Disadvantages of summative assessments are they can be expensive and complex to introduce and maintain, and they tend to ossify the learning experience leading trainees to become focused on knowing only what is necessary to pass an exam or to achieve a particular set of objectives to the detriment of the spirit of learning and research.
The majority of the respondents (78\%) would favor a standardized evaluation process that would require them to prepare their RA fellows for a summative end of training assessment. ${ }^{24}$ Instituting standard assessments (eg, an international exam) for RA fellows may appear, on the surface, a simple and robust process that could be relatively easily administered. There would, nonetheless, be some major drawbacks. Cooperation and agreement between stakeholders would be a challenge. Cost and administration are also key logistical barriers. Perhaps more importantly, what is the value of theoretical examination in a field where practical skills and technical ability play an equal or more vital role in proficiency? Even if a simple and effective means to ensure standards in RA fellowship education could be agreed upon, this might not necessarily advance the field. An evolution in this direction may foster a culture of exclusivity that could limit growth of the field and ultimately decrease the likelihood for patients to benefit from a larger pool of physicians who have the skills and confidence to utilize RA.

\section{Limitations}

Despite the great lengths taken to identify every RA fellowship program worldwide, there are undoubtedly a number that were missed. Although ASRA publishes a list of all their affiliated fellowships, even this list was not comprehensive. We were not able to identify any such consolidated listings outside North America, so we relied on internet searches and word-of-mouth for identification. Almost certainly underrepresented are RA fellowships in non-English-speaking countries.

This study had a response rate of $66 \%$ which is very good compared to the average rate for online surveys of $12 \%-26 \%$ reported by Scott et al; ${ }^{25}$ there is also an even distribution of respondents across different countries. These results, nevertheless, may contain bias if (1) fellowships with poorer education and experience chose not to respond or (2) responders reported favorably to disguise inadequacies in their programs; both cases would lead to overly positive results. Also, the response may be biased by structural variations in training; Europe for instance does not have as many dedicated regional fellowships as North America, but clinical training in RA is achieved in many centers to a high standard during "residency" or postgraduate clinical training. Inconsistent reporting may compromise the transparency and reproducibility of survey reports as well. ${ }^{26} \mathrm{~A}$ concurrent survey of the RA fellows themselves might provide a more frank opinion on the quality of the fellowship experience, 
but it too would suffer from inherent bias and would present greater logistical challenges to complete. A further limitation is that there is no control and comparison group. The survey of RA fellows by Neal et a ${ }^{16}$ in 2005 cannot be fairly used, given the different questions asked and the separation of time. The authors feel obliged to acknowledge that their own fellowship program and fellowship programs with shared academic affiliations were included in this study.

\section{Conclusion}

This survey illustrates the international scope and continuing expansion of education in the field of RA and points toward a promising future for this subspecialty. The results should be of interest to RA fellowship directors seeking to benchmark and improve their programs, and to faculty involved in further curriculum development. While the survey also demonstrates that there are key experiences common across RA fellowship programs, wide variation does exist. Any effort toward the promotion of standards across RA fellowship programs must closely consider the nature and significance of this variation.

Curriculum guidelines have yet to demonstrate improved outcomes in medical education and training,,$^{27,28}$ and even when curricula are published it is not always mandatory to follow them. Have curriculum guidelines such as those established by ASRA helped to achieve a more comprehensive and standard RA fellowship model? It is hard to say without comparative data. Nevertheless, our survey suggests that the majority of programs offer RA fellows a broad range of educational and practical experience. For the foreseeable future, individual institutions will be responsible for maintaining the quality of their program and ensuring appropriate standards are achieved by their RA fellows.

\section{Disclosure}

The authors report no conflicts of interest in this work.

\section{References}

1. Sites BD, Neal JM, Chan V. Ultrasound in regional anesthesia: where should the "focus" be set? Reg Anesth Pain Med. 2009;34(6):531-533.

2. Marhofer P, Harrop-Griffiths W, Kettner SC, Kirchmair L. Fifteen years of ultrasound guidance in regional anaesthesia: part 1. Br J Anaesth. 2010;104(5):538-546.

3. Bartusseck E, Fatehi S, Motsch J, Grau T. Survey on practice of regional anaesthesia in Germany, Austria, and Switzerland. Part 1: quality assurance and training concepts. Anaesthesist. 2004;53(9):836-846. German.

4. Kopacz DJ, Neal JM. Residency training: the year 2000. Reg Anesth Pain Med. 2002;27(1):9-14.

5. Smith MP, Sprung J, Zura A, Mascha E, Tetzlaff JE. A survey of exposure to regional anesthesia techniques in American anesthesia residency training programs. Reg Anesth Pain Med. 1999;24(1):11-16.
6. Hargett MJ, Beckman JD, Liguori GA, Neal JM; for Education Committee in the Department of Anesthesiology at Hospital for Special Surgery. Guidelines for regional anesthesia fellowship training. Reg Anesth Pain Med. 2005;30(3):218-225.

7. Regional Anesthesiology and Acute Pain Medicine Fellowship Directors Group. Guidelines for fellowship training in Regional Anesthesiology and Acute Pain Medicine: Second Edition, 2010. Reg Anesth Pain Med. 2011;36(3):282-288.

8. SurveyMonkey. Create surveys. Get answers.Available from: http:// www.surveymonkey.com. Accessed May 01, 2013.

9. Smith HM, Kopp SL, Jacob AK, Torsher LC, Hebl R. Designing and Implementing a Comprehensive Learner-Centered Regional Anesthesia Curriculum. Reg Anesth Pain Med. 2009;34(2): 88-94.

10. Bröking K, Waurick R. How to teach regional anesthesia. Curr Opin Anaesthesiol. 2006;19(5):526-530.

11. Kessler J, Bolger AF, Gray AT. An essential skill. Reg Anesth Pain Med. 2006;31(6):498-500.

12. Tsui BC, Dillane D, Pillay J, Ramji AK, Walji AH. Cadaveric ultrasound imaging for training in ultrasound-guided peripheral nerve blocks: lower extremity. Can J Anaesth. 2007;54(6):475-480.

13. Lirk P, Colvin JM, Biebl M, et al. Evaluation of a cadaver workshop for education in regional anesthesia. Anaesthesist. 2005;54(4):327-332. German.

14. Shorten GD, O’Sullivan O. Simulation for training in ultrasound-guided peripheral nerve blockade. Int Anesthesiol Clin. 2010;48(4):21-33.

15. Neal JM. Education in regional anesthesia; caseloads, simulation, journals, and politics: 2011 Carl Koller lecture. Reg Anes Pain Med. 2012;37(6):647-652

16. Neal JM, Kopacz DJ, Liguori GA, Beckman JD, Hargett MJ. The training and careers of regional anesthesia fellows - 1983-2002. Reg Anesth Pain Med. 2005;30(3):226-232.

17. Johnson T. Counterbalancing clinical supervision and independent practice: case studies in learning thoracic epidural catheter insertion. Br J Anaesth. 2010;105(6):772-776.

18. Kennedy TJ, Regehr G, Baker GR, Lingard LA. Progressive independence in clinical training: a tradition worth defending? Acad Med. 2005;80(Suppl 10):S106-S111.

19. Schmidt RA, Young DE, Swinnen S, Shapiro DC. Summary knowledge of results for skill acquisition: support for the guidance hypothesis. J Exp Psychol Learn Mem Cogn. 1989;15(2):352-359.

20. Schmidt RA, Young DE. Methodology for motor learning: a paradigm for kinematic feedback. J Mot Behav. 1991;23(1):13-24.

21. Schmidt RA, Lee TD. Augmented feedback, In: Motor Control and Learning: A Behavioral Emphais, 5th ed. Champaign, IL: Human Kinetics; 2011:393-405.

22. Epstein RM. Assessment in medical education. $N$ Engl J Med. 2007; 356(4);387-396.

23. Glickman CD, Gordon SP, Ross-Gordon JM. SuperVision and Instructional Leadership: A Developmental Approach, 7th ed. Boston, MA: Allyn and Bacon; 2009.

24. Bodenham AR. Editorial II: Ultrasound imaging by anaesthetists: training and accreditation issues. Br J Anaesth. 2006;96(4):414-417.

25. Scott A, Jeon SH, Joyce CM, et al. A randomised trial and economic evaluation of the effect of response mode on response rate, response bias, and item non-response in a survey of doctors. BMC Med Res Methodol. 2011;11:126.

26. Story DA, Gin V, na Ranong V, Poustie S, Jones D; for ANZCA Trials Group. Inconsistent survey reporting in anesthesia journals. Anesth Analg. 2011;113(3):591-595.

27. Grabowski WS, Redd RA, Cunningham BE, Hartshorne MF, Timmons JH, Truwit CL. A categorical course curriculum for radiology residencies. Invest Radio1. 1988;23(4):312-315.

28. Chudgar SM, Cox CE, Que LG, Andolsek K, Knudsen NW, Clay AS. Current teaching and evaluation methods in critical care medicine: has the Accreditation Council for Graduate Medical Education affected how we practice and teach in the intensive care unit? Crit Care Med. 2009; 37(1):49-60. 


\section{Publish your work in this journal}

Local and Regional Anesthesia is an international, peer-reviewed, open access journal publishing on the development, pharmacology, delivery and targeting and clinical use of local and regional anesthetics and analgesics. The journal welcomes submitted papers covering original research, basic science, clinical studies, reviews \& evaluations,

guidelines, expert opinion and commentary, case reports and extended reports. The manuscript management system is completely online and includes a very quick and fair peer-review system, which is all easy to use. Visit http://www.dovepress.com/testimonials.php to read real quotes from published authors.

Submit your manuscript here: http://www.dovepress.com/local-and-regional-anesthesia-journal 